\title{
Article
}

\section{Developing individuals whilst managing teams: perspectives of under 21 coaches within English Premier League football}

Dowling, Chris, Reeves, Matthew J., Littlewood, Martin A, Nesti, Mark and Richardson, Dave

Available at http://clok.uclan.ac.uk/25212/

Dowling, Chris, Reeves, Matthew J. ORCID: 0000-0002-3903-2910, Littlewood, Martin A, Nesti, Mark and Richardson, Dave (2018) Developing individuals whilst managing teams: perspectives of under 21 coaches within English Premier League football. Soccer \& Society, 19 (8). pp. 1135-1150. ISSN 14660970

It is advisable to refer to the publisher's version if you intend to cite from the work. http://dx.doi.org/10.1080/14660970.2018.1432381

For more information about UCLan's research in this area go to http://www.uclan.ac.uk/researchgroups/ and search for <name of research Group>.

For information about Research generally at UCLan please go to http://www.uclan.ac.uk/research/

All outputs in CLoK are protected by Intellectual Property Rights law, including Copyright law. Copyright, IPR and Moral Rights for the works on this site are retained by the individual authors and/or other copyright owners. Terms and conditions for use of this material are defined in the policies page. 


\section{Developing Individuals whilst Managing Teams: Perspectives of}

\section{Under-21 Coaches within English Premier League Football}

Chris Dowling, ${ }^{1}$ Matthew J. Reeves,${ }^{2,3}$ Martin Littlewood, ${ }^{1}$ Mark Nesti, ${ }^{1}$ and David Richardson ${ }^{1}$

${ }^{1}$ School of Sport \& Exercise Sciences, Tom Reilly Building, City Campus, Byrom Street, Liverpool, L3 $5 A F$.

${ }^{2}$ Sport Coaching Research Group, Liverpool John Moores University, IM Marsh Campus, Barkhill Road, Liverpool, L17 6BD.

${ }^{3}$ Research In Sport, Liverpool, UK.

Email: c.dowling@2009.ljmu.ac.uk 


\section{Developing Individuals whilst Managing Teams; Perspectives of Under21 Coaches within English Premier League Football}

The Elite Player Performance Plan (EPPP) and recent football culture literature has recognised the phase beyond the academy to first team transition in elite level football, termed the Under21 level by the EPPP. The aim of this study was to explore Under21 Development coaches' thoughts, perspectives, and approaches within this phase of development at English Premier League football clubs. Data was collected via one-to-one semi structured interviews with six Under21 Development coaches from six different English Premier League Clubs. The data collected was subjected to a thematic analysis. Results suggested Under21 Development Coaches were situated, culturally and sometimes physically, inbetween the academy and first team environments, often trapped between two distinct cultures. Under 21 coaches also had contrasting views and approaches with regards to the development of Under21 players and the importance of winning at this stage of development. Under21 coaches appeared to favour creating an environment that can replicate a first team environment to prepare Under21 players for the first team. The study concludes by proposing more support for Under 21 development coaches with regards to clarity of the role and developing players, from relevant stakeholders such as the EPPP.

Keywords: player development, elite football, English premier league, under21, development coach 


\section{Introduction}

Not since 'The Class of 92' has a FA Youth Cup team produced so many professional players who have gone on to play in the English Premier League (EPL). 'The Class of 92' consisted of six academy FA Youth Cup winning players who successfully 'graduated' to the first team of Manchester United FC. However, more recently, the percentage of EPL academy players successfully transitioning to the first team has reached a new low, with only $11.7 \%$ of EPL clubs players 'graduating' from their own academy. ${ }^{1}$ Furthermore, it was identified that during the period 2004-05 to 2008-09 the English Premier League had the second lowest number of indigenous home grown players out of the 'big five' (EPL, Bundesliga, French Ligue 1, Serie A, and La Liga). ${ }^{2}$ Indeed, it is reported that less than one percent of academy football players will play professional football for a living. ${ }^{3}$ This trend has continued, with the Poli, Ravenel and Besson $^{4}$ reporting that overseas players account for $59.9 \%$ of EPL football players, the second highest in Europe behind Cyprus. Concerns relating to the declining homegrown talent were addressed by the EPL, and a new long term vision to modernise youth development was discussed, and in 2011 a new strategy was implemented defined as the Elite Player Performance Plan (EPPP). ${ }^{5}$ Within the EPPP, a major modification was the traditional 'Premier Reserve League' changing to the 'Premier Under 21 League', and thus forms the base of this study. This phase of development is often referred to as the 'developing mastery phase' ${ }^{6}$ or 'post academy phase'. ${ }^{7}$ It has been acknowledged as an important part of the development journey for professional footballers, ${ }^{8}$ though, to date, no empirical research has been attempted to examine this specific phase of development within elite level football. 


\section{The Developing Mastery Phase}

Under the EPPP ${ }^{9}$ the newly created Professional Development League (PDL) covered the under 21 age group. To be eligible, players must be aged 21 or under to be eligible, however, teams are allowed one over-aged goalkeeper and three over-aged outfield players on a team sheet $(n=18)$ at any one time. The aim of the PDL, in particular for those aged under 21 , is to provide "an environment where they can learn to win" and should "replicate the professional game" 10 whilst still allowing time to develop before transitioning to the first team. This aligns with previous calls in the literature ${ }^{11}$ which have advocated more supportive, development orientated environments for 18-21-yearold elite level football players.

Richardson et al. ${ }^{12}$ proposed a football specific transition model, adapted from Wylleman and Lavallee, ${ }^{13}$ which depicts the potential development pathway for elite young football players and the within-career transitions that elite young football players will face. The model suggested that within the 'developing mastery' phase, players are often isolated, lonely, and uncertain due to the typical cultural context of EPL football clubs. Furthermore, it suggested that players in this phase often lack social support, whilst having to often develop relationships with new coaches, often from the first team environment. ${ }^{14}$ In addition, it has been highlighted that there is a need for clubs to create supportive yet challenging environments were young players between the academy and first team can flourish. ${ }^{15}$

Earlier work supports these ideas, where first team managers proposed the creation of more supportive environment for young professional players to enable them to develop their character, step away from the comfort zone of the academy and forge new identities as first team players. ${ }^{16}$ This more supportive environment advocated by the first team manager is often more associated with the academy where a process 
oriented and caring culture is more likely to exist, allowing more time for development to occur. ${ }^{17}$ However, it has been suggested that at approximately 18 years of age, athletes enter a 'training to win' phase were a focus on 'optimising performance' is essential. ${ }^{18}$ It would seem pertinent to explore the notions of 'optimising performance' and 'training to win'19 against the, potentially, contrasting 'supportive environment' advocated elsewhere. ${ }^{20}$

\section{Coaches' Role in Youth Development}

Talent development research suggests that the role of the coach often changes as an athlete develops and progresses from the beginning stages of development through until the young athlete reaches higher levels of their chosen sport. ${ }^{21}$ Specifically, Bloom ${ }^{22}$ and later van Rossum ${ }^{23}$ identified how during the initial, early stages of development, coaches appear to be supportive, caring, positive and motivating in their approach. However, during the development years (which varied within the different disciplines and sports studied) and beyond, it was suggested that coaches become stricter, distant and very critical of the young athletes. ${ }^{24}$ Bloom ${ }^{25}$ also suggests that during the 'middle' and 'perfection' years coaches are more disciplined, demanding, and focused on the perfection and precision of a skill, whereas van $\operatorname{Rossum}^{26}$ suggested that during the development and mastery years, coaches still acted in a positive, motivating, and inspiring manner. It appears throughout the middle and later years of development, coaches tend to be more subject or outcome orientated; with a greater emphasis on the athlete's future professional career as opposed to caring about the 'person'. ${ }^{27}$

Nesti and Sulley, ${ }^{28}$ whose work is specifically concerned with applied practice in football, argue coaches' philosophies at the best football clubs are always playercentred. However, player-centred does not necessarily mean the experience is any 'softer' or 'easier' for players. Indeed, they suggest that as the player develops and 
progresses through the academy system, coaches often place players in stressful and anxiety producing situations. This approach is suggested as a vital component of preparing players for the intense, pressurised environment of the first team. ${ }^{29}$ Perhaps, with regards to professional football at least, coaches only appear more distant as the player develops in an effort to urge players to take more responsibility, improving players' self-awareness and developing a strong identity. ${ }^{30}$ Nesti and Sulley ${ }^{31}$ suggested that whilst lower level professional football clubs may have a more autocratic style with players in the academy system, the elite level clubs tend to allow the players space to find their own solutions with the idea of players becoming their own coaches as they move 'through the ranks'.

Previous research has suggested the first team environment can be brutal, ruthless, and macho ${ }^{32}$, whilst the academy environment tends to be 'softer' ${ }^{33}$ However, there is also empirical work to suggest that academy coaches often tend to create tough, brutal environments for players. ${ }^{34}$ Indeed, Cushion and Jones ${ }^{35}$ highlighted how the general context of conversation was exclusively coach led, with such language shaping the coaches' and players' relationships, behaviours and interactions amongst one another. Although coaches were perceived to be aggressive, such methods often "reflect traditional institutional discourse within the sport and hence have been accepted as a kind of occupational hallmark". ${ }^{36}$ These harsh, and often confrontational, coaching behaviours appear to be deeply rooted in the culture of professional and elite football in the UK and almost viewed as an essential feature in the preparation of young talented players for a life within the game. ${ }^{37}$ This might suggest that that the academy and youth football culture may, in actuality, possess an element of ruthlessness and brutality, and is only perceived to be more 'supportive' and 'softer' when compared to the 'extreme brutality' of the first team environment. 
Studies have highlighted the different approaches that coaches can adopt depending on their personal character, beliefs and values, acceptable culture of their sport and, additionally, the 'age and stage' of the athlete. ${ }^{38}$ The philosophy, role, and function of the coach still has a significant influence on athlete development throughout their career. ${ }^{39}$ Whilst studies have examined the academy-to-first-team transition in professional football ${ }^{40}$ from a range of stakeholders such as players, parents, coaches, research has yet to examine the role of this 'new' development coach and its impact upon player development with regards to transitioning to the first team. ${ }^{41}$ EPL Under 21 coaches in particular are worthy of study due to their relative newness within elite level football and the proposed importance placed on them by both the Football Association and the Premier League. Therefore, this study will seek to explore the role, practices, and approaches of coaching working in the development of mastery phase within elite level football.

\section{Methodology}

A qualitative approach, utilising an exploratory study design was adopted for this study. The exploratory research design was deemed appropriate given its flexibility to adapt during the study, a common feature of applied practice studies, such as this. Furthermore, an exploratory study design would also be beneficial for better framing future studies in this, so far, under-examined area of inquiry. By adopting a naturalistic approach, it was hoped that the study's exploratory design would provide better contextspecific understanding of the phenomenon under investigation. ${ }^{42}$ It is also suggested that Furthermore, Jones, Hanton, and Connaughton (2002) adopting a qualitative approach allows the researcher to develop a comprehensive understanding about the participant's personal paradigms, perspectives, and experiences, therefore characterising the surrounding environment. ${ }^{43}$ 
Data were collected by means of semi-structured interviews. The interview schedule was carefully designed to explore the cultural and environmental challenges experienced by the under 21 development coaches within their respective club. The interview schedule was developed deductively alongside previous talent development literature ${ }^{44}$ and relevant football culture literature. ${ }^{45}$ A pilot interview was conducted with a full-time academy coach, which was reviewed by the research team. Following the pilot interview there were several small amendments to question ordering to allow for better flow between topics covered. ${ }^{46}$

\section{Procedure and Sampling}

Letters were sent to all EPL academy directors, which included the overall aim of the study, and the data collection process along with the primary researchers contact details. Three coaches replied positively, inviting the principal researcher to their club to conduct data collection. From there, a snowball sampling method was adopted ${ }^{47}$ where the researcher utilised the contacts of those already involved in the data collection process to recruit others to the study, which led to a further three interviews being completed. Overall, six individual, face-to-face semi-structured interviews were conducted with under 21 development coaches over a period of eight months. Each interview took place at each participants' respective club facilities. All interviews were digitally recorded using a Dictaphone. Interviews ranged between 45 and 80 minutes in length (total=383 minutes; $M=63.8$ minutes).

\section{Participants and Setting}

To enable the reader to become familiar with each participant, the table below briefly introduces each participant, providing details on their involvement in football and their personal background. 
Table 1: Pen pictures of participants

\begin{tabular}{|c|c|}
\hline Coach \& Club & Contextual Information \\
\hline $\begin{array}{l}\text { Marc Williams } \\
\text { (Allerton City) }\end{array}$ & $\begin{array}{l}\text { Marc had a successful playing career for various clubs within League } 1 \text { and the } \\
\text { Championship. Towards the end of his career, Marc was asked by his first team } \\
\text { manager to become the assistant manager. Marc already had his UEFA B License, } \\
\text { Marc then worked at two different football league clubs in assistant managerial roles } \\
\text { before coming to Allerton City as under18s development coach before making the } \\
\text { move to under21s coach. Allerton City are a well-established Premier League side, } \\
\text { having over } 10 \text { years' experience within the Premiership. }\end{array}$ \\
\hline $\begin{array}{l}\text { Jordan Ager } \\
\text { (Bowring FC) }\end{array}$ & $\begin{array}{l}\text { Jordan played professional football from the age of } 18 \text { through to the late 20s. Jordan } \\
\text { took his coaching badges whilst playing and, at the age of } 29 \text {, left professional } \\
\text { football to pursue a career in "football coaching and management". Jordan coached } \\
\text { and managed at various youth and first team roles at clubs within the football league } \\
\text { before joining an English Premier League club as a development coach. Jordan was } \\
\text { there for numerous years before making the switch to Bowring FC as under21 } \\
\text { development coach. Bowring FC are one of the top Premier League sides in England } \\
\text { and have a vast amount of experience playing in the UEFA Champions League. }\end{array}$ \\
\hline $\begin{array}{l}\text { Adam Fairclough } \\
\text { (Crosby Town) }\end{array}$ & $\begin{array}{l}\text { Adam had a successful playing career with numerous football league clubs. Adam } \\
\text { was never "100\% convinced" about coaching due to his desire to return to his home } \\
\text { country. Adam enrolled on the UEFA B Licence whilst still a player and "quite } \\
\text { enjoyed it". The first team manager at Crosby Town, who previously had worked } \\
\text { with Adam at another club, offered Adam a job at Crosby Town under the role of } \\
\text { development coach. Crosby Town are one of the smaller Premier League clubs, } \\
\text { however they have maintained their Premier League status for over } 7 \text { years. }\end{array}$ \\
\hline $\begin{array}{l}\text { Shane Whelan } \\
\text { (Brentwood FC) }\end{array}$ & $\begin{array}{l}\text { Shane started his career as a player, however Shane only ever played at youth and } \\
\text { reserve team level before switching to coaching, where he gained his A Licence. } \\
\text { Shane has coached for over } 30 \text { years. Within that time, Shane has had various youth } \\
\text { and reserve team coaching roles at a number of clubs and has also had a spell as a } \\
\text { first team manager. Furthermore, Shane has also coached nationally at under } 21 \text { level. } \\
\text { It is now Shane's } 3^{\text {rd }} \text { year as Development Coach at Brentwood FC. Brentwood FC } \\
\text { are currently operating within the English Premier League. }\end{array}$ \\
\hline $\begin{array}{l}\text { Rob Lynn } \\
\text { (Netherley FC) }\end{array}$ & $\begin{array}{l}\text { Rob retired from professional football in } 2008 \text { due to an injury. Rob had a successful } \\
\text { footballing career, playing for many Premiership and Championship sides. On one of } \\
\text { Rob's visits to his former club, the first team manager asked if he'd like to come and } \\
\text { do some coaching sessions. Rob started out as an assistant under } 21 \text { coach, over } \\
\text { months Rob began to take more and more sessions and in } 2009 \text { was appointed } \\
\text { Reserve Team Manager of Netherley FC. Netherley FC are a well-established } \\
\text { Premier League side who have maintained their Premier League status since its } \\
\text { change from the old First Division in } 1992 \text {. }\end{array}$ \\
\hline $\begin{array}{l}\text { Kieran Campbell } \\
\text { (Huyton Athletic) }\end{array}$ & $\begin{array}{l}\text { Kieran started his playing career at one of the top Premier League clubs, playing a } \\
\text { handful of games before being released. Kieran played for numerous lower league } \\
\text { English football clubs. Kieran began to take his coaching badges whilst he was still } \\
\text { playing and now has the Pro Licence Coaching Badge. Kieran has been at Huyton } \\
\text { Athletic for } 4 \text { years, after starting out coaching on an exchange programme. Kieran } \\
\text { was appointed as the lead coach for the } 12-16 \text { age groups before being asked to be the } \\
\text { Under } 21 \text { Development Coach. Huyton Athletic is one of the top Premiership clubs in } \\
\text { the league and regulars in the Champions League. }\end{array}$ \\
\hline
\end{tabular}

\section{Data Analysis}

Data were thematically analysed, utilising the six-step process suggested by Braun and

Clarke. ${ }^{48}$ Firstly, interviews were transcribed verbatim and a tagging system was 
adopted within the data analysis, which replaced the coaches' names with pseudonyms (see above) to ensure confidentiality. As advocated elsewhere, ${ }^{49}$ a combined approach of deductive and inductive analysis was adopted. Analysis started deductively based on the previous talent development and culture in professional football literature, whilst also being aware of inductive themes emerging from the data.

The primary researcher became immersed in the data, reading and rereading transcripts. ${ }^{50}$ From here, initial codes were identified from the raw data. Once all raw data had been coded and collated, the primary researcher began to develop themes based on the initial codes. A thematic map was developed to assist in developing the different codes into themes (see Figure 1). ${ }^{51}$ These themes were consistently reviewed and refined through two levels of analysis: Firstly, checking to see if the themes work in relation to the codes, and secondly coding across the data for any additional data within themes that may have been missed. Once the thematic map was deemed as 'working' and 'meaningful', 52 through methods of triangulation the research team met to further analyse the themes suggested by the primary researcher. ${ }^{53}$ Lastly, the research team met to define and name the final agreed themes. ${ }^{54}$

\section{Data Representation}

Flexibility as a key requirement of thematic analysis, giving freedom to the researcher to capture the themes pertinent to the phenomenon being explored. ${ }^{55}$ Furthermore, Sparkes and Smith ${ }^{56}$ highlighted how themes within a thematic analysis will not naturally fall neatly in to one category, as themes often have similar concepts and may overlap. The development of a thematic map supported this idea and helped to visually demonstrate the overlaps that were apparent within the data. Following this, descriptive verbatim quotes from the themes are presented, discussed and critiqued alongside previous research central to the development of this study ${ }^{57}$ However, it must also be 
noted that this study was part of a much larger research project, and only some of the key themes pertinent to the under 21 coach and it is their perspectives that are included in this study.

\section{Findings and Discussion}

Three main themes emerged from the data analysis: "The Inbetweeners", "Development \& Winning" and "Creating an Environment". These themes are inherently linked and interconnected and, therefore, presented as such within the thematic map.

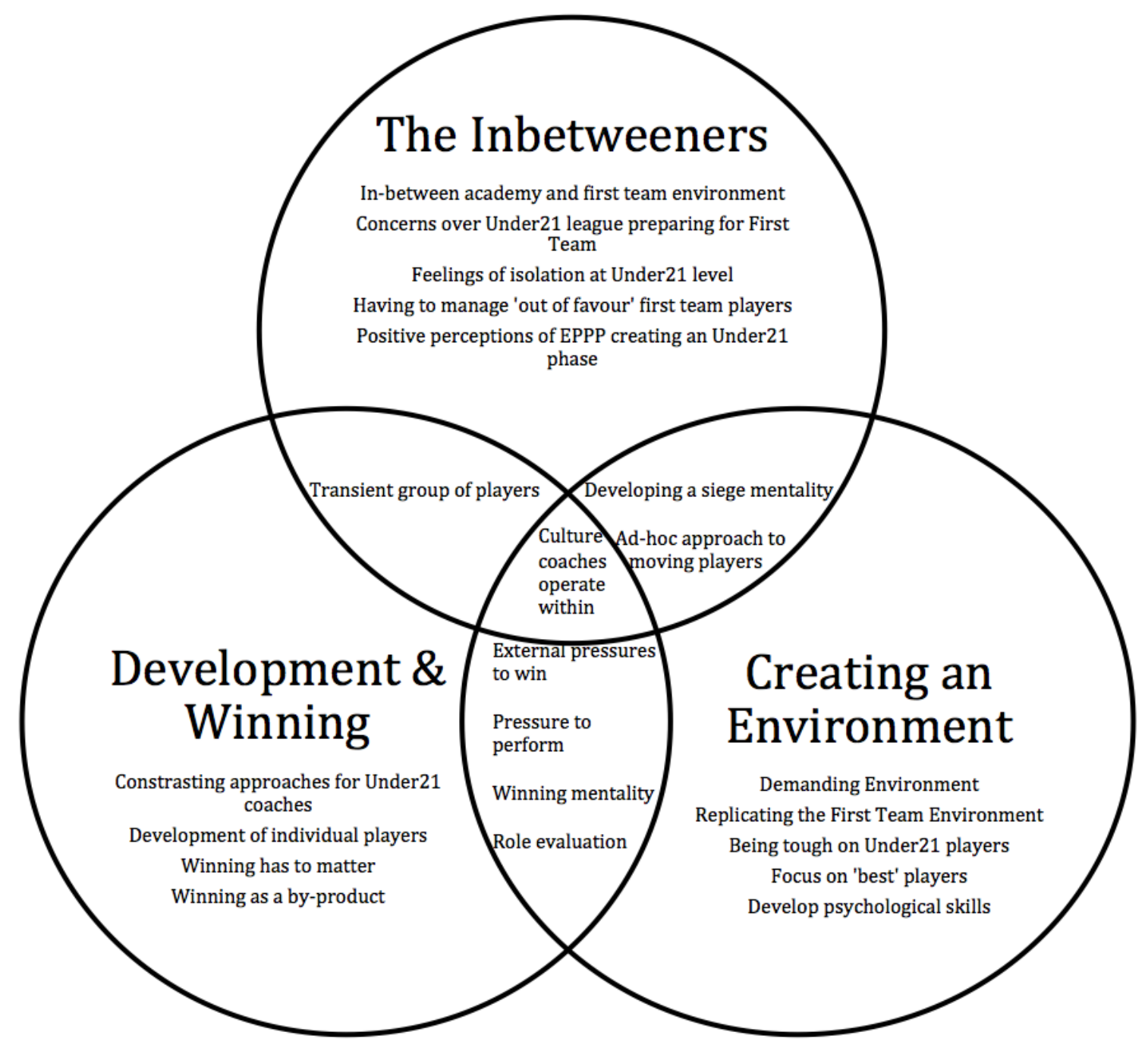

Figure 1: Thematic map of findings 


\section{The Inbetweeners}

The EPPP ${ }^{58}$ and more specifically the Professional Development League, was created in an attempt to develop a more fluid connection between the academy and first team environments. The cultural distance, and sometimes physical distance, between academy and first team environments has been regularly highlighted and discussed in research within professional and elite level football. ${ }^{59}$ Participants highlighted that a positive aspect of the implementation of the EPPP was, as Shane suggested, an improved "link between the academy and first team:"

\footnotetext{
"It's all changed with the EPPP... academies are now 21s down, so [before] it's always been really tight for the academy for $18 \mathrm{~s}$ down... the support structure we've got for the boys is brilliant but then the reserve team was always a different age and came under the first team, but because of the new structure now it's sort of like a little bit in-between the two..." [Marc - Allerton City]
}

"To be fair, credit to the EPPP, that has come in and recognized the issue, created a league for the players during this development, you know basically the under21 players and we've gone from strength to strength." [Shane - Brentwood FC]

Although participants seemed to approve the creation of what 'developing mastery' phase ${ }^{60}$ and specifically an under 21 league for the players, clubs appeared to differentiate with regards to the location of the $21 \mathrm{~s}$ within the organisational structure of each club. In this regard, Bowring FC was the only club whose developing mastery phase appeared to be positioned, both physically and culturally within the academy structure. Contrary to this, Huyton Athletic, Crosby Town and Netherley FC positioned their developing mastery phase within the first team environment: 
"We've got the under18s, the under 21s and the first team [located within the same building]. It is all a chain reaction, this season with the under21s we've had one or two that have moved up into the first team and they train with the first team a lot." [Adam - Crosby Town]

"The $21 \mathrm{~s}$ are located on the first team side of the building, we're located next to the first team because we have to sometimes be close to them when we train because they might need us to train with them, or they might need a couple of our lads to join in to make their numbers up." [Rob - Netherley FC]

Data suggest that Crosby Town and Nethereley FC may have a similar ad-hoc approach whereby under21 players can be 'promoted' or 'called up' to the first team if required by the first team manager. However, both coaches reported 'promotion' to the first team might could range from being just for one game or for the remainder of the season. Rob identified the "18-21 development phase" as a "link to the first team and the academy/18s mainly". Similarly, Brentwood FC's developing mastery phase players were situated in-between the academy and first team environments:

\footnotetext{
"we are in-between the academy and the first team... I think it's too big a gap to go from under18s [to the first team]; as an 18s player unless you're really exceptional physically and/or tactically... the basis of the under21s is that it gives the players an extra 2 years." [Shane - Brentwood FC]
}

The above section briefly describes the organisational structure of the under 1821 phase of development, and highlighted some of the structural differences between the clubs involved within the research. ${ }^{61}$ The creation of the under 21 competition within the EPPP was to provide an opportunity to "replicate the professional game" in both competition and training ${ }^{62}$ while providing time for young players to develop. However, data suggest that this is, perhaps, not occurring quite how was intended. The range of different approaches to the physical and symbolic positioning of this cohort of 
players remains unclear. The following sections explore the notion of creating the right culture to successfully develop players within the 18-21 mastery development phase.

\section{Development and Winning within Elite Level Under21 Football}

Previous work has discussed the idea of long-term athlete development and the ages and stages of development for athletes. ${ }^{63}$ Within these stages, it is suggested that athletes experience a 'training to win' stage around 17-18 years of age. ${ }^{64}$ Whilst the model lacks scientific rigour and isn't specific to professional football within elite UK contexts, it is of interest to note the suggestion of a shift in focus to 'optimising performance' at this 'training to win' stage of development. ${ }^{65}$ Of the six coaches who participated in this study, Kieran, Shane, Adam and, to an extent, Rob, highlighted the importance of the under 21s winning games within their approach, and also the importance of competing in tournaments, as Shane explains:

\footnotetext{
"Winning matters massively to me. That's what I like to do as a youth team coach, I like to win and we were the best once. That was a great achievement for our sides when we've got to finals and such, winning has always been high up on the agenda for me, rightly or wrongly."
}

Furthermore, Adam suggests that "losing is not an option, well I wouldn't say it's not acceptable, but losing is not... losing is not what we're trying to achieve." Similarly, Kieran, a coach at one of the top clubs within the EPL, also highlighted the importance of winning at this stage of development:

\footnotetext{
"Winning is very important, especially at the under21s age group. When it's with the younger groups it matters less as its developing techniques and stuff. But at the under21s, I think it's very important. You know, football is about winning, we look to go into every game to win, and we take winning at this level very seriously."
} 
Kieran suggests how, as young talented football players develop and progress through the age groups within academies, winning games becomes more of a priority, in particular for the developing mastery phase. Shane also highlights that, as players progress through the academy and nearer the first team environment, "winning becomes paramount”. Nevertheless, Marc's (Allerton City) and Jordan's (Bowring FC) approaches remain focused towards the individual development of players. Here, Marc highlights how the important the contact that he has with his players is during training sessions throughout the week.

"I'm a firm believer in getting them to do the right thing, get your work done through the week and doing the right thing in games and the winning is a byproduct of doing the right things; now the fact we've won is great, use it for whatever; but in reality that's not that important (at this stage)."[Marc]

Whilst Marc suggests its "great" to win the game, he also suggests the game in itself isn't that important. This aligns with previous work which has called for clubs to create more supportive environments for individual players to develop, in a team environment. ${ }^{66}$ In addition, Jordan appeared to hold strong values in relation to his coaching philosophy and the importance he placed on the development and improvement of individuals rather than the whole team during the development of mastery phase:

\footnotetext{
"My job is to improve individuals. I don't care about the team. The team isn't going to make a debut! The individual is going to make a debut. So the team needs to carry the individual and it's got to be healthy and if you do it right for the individuals, the team will come together." [Jordan]
}

The EPPP,${ }^{67}$ however, suggests the under 21 league should replicate the professional game were winning is considered essential. Whilst the espoused values of the EPPP are augmented toward winning at this stage of development, literature 
suggests that this proliferates into younger age groups and, thus, stages of development. ${ }^{68}$ This 'win at all costs' mentality can often be counterproductive and detrimental to the individual development of the athlete and even negatively impact future team performance. However, whilst Rob highlighted his players are under no pressure to win, an important part of his approach was to make the players aware that their careers will be based on results and, therefore, the winning of football matches:

\footnotetext{
"We need to be careful it's not just about developing and don't give them that feeling of winning, because it's a very difficult element of the game to give them. You can develop as an individual, you can develop as a group, as a team, I think if you do that then automatically winning can just blend into that. I think it's important that the players are under no pressure to win, but they have to realise that one day that is what they're playing (professional) football for." [Rob]
}

The motivational climate and associated win-loss ratios within youth sport has previously been examined. ${ }^{69}$ The direct application of Cumming and colleagues ${ }^{70}$ study to this particular cohort and environment is of clear question, yet their study provides a useful basis upon which critical questions should be asked of the importance and impact of a 'win at all costs' mentality within junior-elite and elite level football. Indeed, their results suggested that a "mastery-involving motivational climate" was positively associated with athletes and the evaluations of their coach, whereas an "ego-involving climate" was negatively related to athletes' evaluations of their coaches. ${ }^{71}$ With regards to this, a 'mastery', or 'task motivational climate' is focused on developing athlete's skills, personal development and reward for effort, contrary to an 'ego motivational climate' which is focused on competition, reward for ability, and competition between teammates. ${ }^{72}$ Here, Rob, of Netherley FC, suggests an approach which aligns to a 'mastery' or 'task' environment: 
"Making them better. That is the best thing we can do... you have to look at a different way of getting them to learn, so you know maybe not by vocal, it may be by visual, so you have to show them then different ways until the penny drops. It might be a couple of years, but you just have to keep knocking on the door. If you keep knocking on the door, keep knocking on the door till someone opens it and lets you in." [Rob]

It is suggested that winning is not an essential factor for the enjoyment of the sport nor liking a particular coach. ${ }^{72}$ Since their seminal study, ${ }^{73}$ there has been a conscious effort within much coach education to reduce the value and importance placed on winning within youth sport. ${ }^{74}$ However, the majority of coach education and talent development research aligning to 'winning' or 'development' is often associated with young adolescents, and not necessarily in professional environments. ${ }^{75}$

Adam and Rob both suggested winning was important to them at this stage of development, but not at all costs. However, it has been identified that too many youth coaches' philosophies within junior-elite and elite football are grounded in winning. ${ }^{76}$ This, perhaps, suggests that there is a wider cultural issue within junior-elite and elite football. Marc continues:

\footnotetext{
"The problem is everyone says, the first thing they say is "what was the score?" that's the question everyone asks you that's football, people do ask; that's it. You know, it sort of shouldn't be but that's the way the game is in this country."[Marc]
}

It appears the research within coach education, ${ }^{77}$ which has attempted to reduce the importance placed upon winning within youth sport, has not been effective in the within junior-elite or elite environments of football. This study has demonstrated that there are a range of thoughts and approaches to winning and development, currently utilised by elite level under 21 football coaches. However, perhaps, the most pertinent question is whether winning is a major factor in the assessment and evaluation of an 
under 21 coach's ability within their respective club. Whilst Shane, Kieran and Adam stated the importance of winning during this phase of player development, four of the six coaches stated that winning was not a factor of how their role was evaluated and assessed:

"I'm probably judged on the quality of the player that will be given or goes to the first team and the level of his understanding, the level of his application and the level of his technical ability." [Jordan]

However, Kieran and Shane highlighted that winning and/or the results of under 21 games was a contributory factor of how their respective roles were evaluated.

"I think the result of the game is certainly one of them. But I also think it's winning with style. You know we have a philosophy and a methodology of playing, so we are judged also on how well we are playing and how our play fits the club's philosophy." [Kieran]

"I think under 21 players as individuals have to realise that they are in an environment where winning is paramount, winning games keeps people in jobs and develops a winning mentality." [Shane]

If, as the previous studies have suggested, the overall aim of a professional football academy is to develop players for the first team, ${ }^{78}$ it must be questioned what value clubs attribute to results in development league and cup competitions. Interestingly, whilst Jordan expressed his personal thoughts and feelings towards individual development, which questioned the value placed upon winning, or at least winning at all costs, he also stated that:

"it's about working with the best players and their needs, and I stress that, it's the best players. You need to concentrate on the development of the players who have a realistic chance of the first team." 
This statement suggests that even individual development was a contested issue, with only 'the best' players with a 'realistic chance' of playing for the first team being focussed upon by coaching staff and having their development better-tailored as a consequence. This could be aligned to an 'ego orientated' environment ${ }^{79}$ which, perhaps, suggests that whilst coaches' philosophies may be focused on the development and improvement of the individual, they still appear to in fact create an ego-orientated environment, where coaches focus on the best players, heightening competition between team-mates. Similarly, Adam's approach to coaching in the mastery development phase aligns with an ego-orientated environment:

\footnotetext{
"We say to them that to get to that next level, you need to try and excel over your group. So whatever you're doing, you need to be better than the guy next to you, and the guy on the other side of you. Push your head above the water and be seen" [Adam]
}

The quotation above highlights the intensified, ego orientated environment that may exist within the developing mastery phase. However, this is not to say a 'task' focus is still not embedded into their coaching practise by these coaches, with research suggesting elite players can often have a mixture of both 'task' and 'ego' traits. ${ }^{80}$

\section{Creating an Environment for Under21 Development Phase}

Whilst the EPPP ${ }^{81}$ indicates that the winning is of significant importance at this stage of development, it might be suggested that the culture and environment created by the coach is more important and that winning is a positive by-product of that culture and environment. ${ }^{82}$ Indeed, previous work has suggested that junior-elite players in English academies need to be better catered for in relation to the psycho-social environments created for players whilst they are developing. ${ }^{83}$ 
"It is important that when we send these players into the first team that they have a fair idea of what to expect, when the manager puts on a session be ready. If they've been involved in that sort of environment before they know exactly what to do, so they don't go in there and get lost. It is one thing to have a natural talent but the manager is also very articulate on the psychological skills... So our environment is to replicate that of the first team and develop those psychological skills" [Adam Crosby Town]

"I make it a very demanding environment for the under21s. It can be seen as tough, or harsh but believe me, they need to be used to that if they want any chance of making it within professional football. I demand a $100 \%$ from them at all times. I do raise my voice at times, I do swear, I do get heated... I try and create the environment they're going to face when they go up to the first team, because my job is to get them to that place. There is no time for development within the first team. The Saturday afternoon result is everything." [Shane - Brentwood FC]

Adam also suggested he would develop "those psychological skills" which are required to be able to "compete" at the first team level. Kieran also highlighted the need for players at this stage to develop a "mental toughness", with Shane stating some of the criteria under 21 players need to 'survive' in the first team:

"If they're not up to it and they can't stand the banter and the criticism and all that goes with being in the first team and they can't handle coming on as a sub in front of 20 odd thousand people, they won't survive."

To give the under 21 coaches' thoughts and perspectives on creating an environment some theoretical context, the work of Henrikson, Stambulova and Roessler ${ }^{84}$ presented a conceptual model of an Athletic Talent Development Environment (ATDE). Their study proposed a shift in focus from the development of individual athletes to the broader environment in which a talented athlete develops. Within the ATDE model a key feature to the success of the environment was to directly surround the 'prospective elite athletes' (i.e. mastery development phase players) with 
the 'current elite athletes' (first team), and 'experts' and 'managers' (from the first team environment). ${ }^{85}$

The study highlighted how successful teams (although the research was not football focused) created an environment where the coach helped to establish close relationships between the prospective elite athletes and the elite athlete themselves. However, as reported previously, ${ }^{86}$ this may prove a difficult task due to the typical physical and/or cultural barriers that exist between development squads and the first team. Furthermore, Henriksen et al.$^{87}$ reported that within one elite level sports club, coaches attempted to create an environment that was, "demanding yet supportive, and providing enough personal space and freedom for the [elite] prospects". With regards to this, Shane and Kieran in particular appeared to favour creating a "demanding environment" where players are "pushed through barriers", "challenged" with a "pressure to perform":

"We look to go into every game to win, and we take winning and performing at this level very seriously... You should be looking to win all of your games and we'll be disappointed if we don't win." [Kieran]

However, Shane and Kieran reported little support via the coaches themselves in place for the developing mastery players. This lack of support was often discussed in relation to "being tough on players" and "not having a constant shoulder to cry on":

\footnotetext{
"We can't speak to the players like I got spoke to in my youth, that's for sure. But we can certainly still be tough with them, it happens in first team football and this is the final step before they go to that, so they have to be ready for it. They have to learn for themselves, and not have a constant shoulder to cry on." [Kieran]
}

In addition, a focus on performance and appropriate development, as opposed to a focus on results and early success has been posited as key to a successful 
environment. ${ }^{88}$ This would appear to align with Jordan and Marc's approaches to developing the individual players ability without a focus on results, and in contrast to Shane's and Kieran's approach of winning and results taking a priority, as Kieran reports below:

\footnotetext{
"I will have to go with winning always. Winning comes first, then how well you play comes after this. I think me and the other coaching staff agree with this. Winning is essential. Nobody ever remembers the losers in sport, or who come second, well I definitely don't." [Kieran]
}

However, it seems essential to note, whilst it is valuable to explore other sporting environments and cultures to improve talent development within elite level football, it has been highlighted that elite football has a unique culture, and any attempt to introduce certain 'key features' from other successful, non-football sporting environments may prove difficult. ${ }^{89}$

The contrasting views and coaching approaches of the under 21 coaches may in fact be due to the culture they operate within. Indeed, whilst the culture of professional football is, in itself, unique, each club also has deep-rooted and entrenched cultural features. Therefore, whilst participants' coaching philosophies should reflect their own personal beliefs and values, there must also be alignment with an academy or club culture. Kieran, who was based at the first team complex, appeared to create a culture that resembled a typical first team environment within elite level football, such as the players need to know "results are everything", and how Kieran is "very tough on them in terms of demanding a $100 \%$." However, whilst Kieran and other coaches operated within the culture that they try to create, Marc highlighted his difficulties in managing and coaching this critical phase of development - somewhat 'trapped' between two distinct cultures in a state of 'flux' or 'limbo': 
"The way it's gone is that at times we're the 'neither here nor their group'; so we're not with the academy but then not with the first team so it was a bit weird. At the start of the season we didn't start particularly well, we did feel alienated and on our own."'[Marc]

However, Marc further stated how he and the other under 21 staff have overcome some of these issues:
"The best way of how we found to cope was we almost created like a siege mentality. As staff we got really, really tight and around the players and just drove the programme for them. We changed the programme, we improved the programme, with the players I think they got loads of attention to the group and loads of attention individually... and they need to understand that it's going to be bloody hard for them you know and if the application is not right we don't accept it." [Marc]

Marc highlights how he created an almost siege mentality for the 18-21 mastery development phase. Siege mentality is a collective state of mind whereby a group feel isolated or oppressed, often used to develop social cohesion among a group. ${ }^{90}$ Whilst a 'siege mentality' may not be suitable for the mastery development phase at all elite level football clubs, it may be essential for under 21 coaches to attempt to create a further sub-culture within their respective organisations. ${ }^{91}$ With regards to this possible sub-culture, Kieran and Adam highlight how they take elements of the academy and first team cultures to create the "right environment" for developing mastery players to develop for the first team:

\footnotetext{
"We accept nothing but the best; me and Freddie agree on this and we'll make sure the environment is a demanding environment... but this is essential to the development of the players. Another thing we do is look at the individual, pick out a weakness and help them develop that into a strength. Although I've said winning is the most important thing, we also know how important it is to develop individual attributes." [Kieran]
} 
"The under 21s standard is a good stepping pathway for the under $21 \mathrm{~s}$ where they can progress to try and get into the first team, so it's all about now integrating the both of them [academy and first team]" [Adam]

It appears that some coaches attempted to create a sub-culture that was not totally distinct from the academy and first team environments, but incorporated elements of both cultures from academy and first team. Whilst not disputing the efforts of the coaches in what appears difficult circumstances, questions must be raised if the creation of an informal sub-culture is fluid and progressive for elite young football players developing within the game. ${ }^{92}$ In relation to this, Marc suggests "it is very much a development approach" and "to go the extra mile for an individual". However, he also stated the importance of "creating a winning mentality" across the group to help develop attributes needed to successfully transition to the first team. It would appear that the creation of a sub-culture, as suggested by participants, to support these 18-21year-old players, was the intended outcome of the $\mathrm{EPPP}^{93}$ which states that "age/phase specialist coaches need to be able to merge the need to learn how to win with the continued need to develop the player technically and tactically". However, whilst this may be an intended outcome the methods and processes for how this might be achieved are less clear.

Whilst coaches suggested that they had a 'solid' group of players where they could create an environment and culture for players to thrive, Jordan identified how he had a transient group of players, which further complicated his approach but also the culture and environment:

\footnotetext{
"It is a real transient group so out of all the groups within the football club, the under21s are the ones which is least like a group or least like a team because, if you think about my week; so, we've just played Childwall United, and coming up from the youth team to help us for that fixture was James Lloyd, Daniel Campbell, Francis Volante, Sean Riley... Shaun Sheedy is a first year but has been playing in
} 
that group all along. Coming down from the first team, who you never have access to, is Jack Jones, Michael Foster, Luke Murphy. Then in between them all you've got your Closes and your Smiths who are with you on a daily basis. So you've probably got three groups coming together to play a game on one day, so it's not a team." [Jordan]

The quotation above highlights the difficult task for the under 21 development coach, where they appear to have to manage players who are at different stages within their development. ${ }^{94}$ Furthermore, it is suggested that during the 'middle' and 'perfection' years of development, coaches can be disciplined, demanding and focused, as opposed to adopting a slightly more supportive culture for younger athletes. ${ }^{95}$ Jordan and Rob identified how they have to work with a range of players who are at different stages of their development with Rob suggesting that he has players "as young as sixteen" in his post academy phase, alongside players "as old as 21 ". This highlights that coaches have to successfully develop and manage vastly different players; that is, players that are at differing technical and tactical ability levels, at different stages in their careers, and at different maturational levels physically, psychologically, and socially. Whilst having to manage and work with players of different ability might be considered essential criteria for elite level coaches, having to work with players so diverse in their development may prove to be a further challenge for these coaches.

\section{Conclusion}

This study attempted to explore under 21 development coaches' thoughts, perceptions, and philosophies on the 18-21 mastery development phase within elite level football. Overall, coaches highlighted positive developments within their respective organisations from the introduction of the EPPP, which included developing stronger links between the academy and first team environments. However, even with the 
implementation of the EPPP clubs have differed in their approach to integrating the mastery development phase into their organisational structure. This demonstrates that this particular phase of development as a conduit between the academy and first team environments with no particular 'right' place to be positioned.

The personal coaching philosophies of participants in this study highlighted some disagreement between their practice and the, potential, suggestions of the EPPP. Indeed, participants reported mixed coaching styles, approaches, and philosophies ranging from strictly development of the individual to winning and a team orientated approach, with some coaches suggesting a combination of both. However, in relation to producing players for the first team, participants indicated that creating the right environment for these players to thrive was an essential part of their role, despite no clarity over what the right environment might be. Furthermore, some coaches highlighted the issue of this being a transient stage of development, making it difficult for coaches to work with such a wide range of players at different stages of development.

This study is the first, to our knowledge, that has explore the role and responsibility of these newly created coaching roles within elite level EPL clubs. The findings of this study suggest EPL clubs need to consider the structure and development pathway for their under 21 players, in relation to their physical location within training facilities and their cultural fit within the organisation. Future studies may benefit from longitudinal qualitative approaches to better examine these phenomenon, including the day-to-day existence of all of those working and living within this critical stage of player development. 


\section{Notes}

1. Poli, Ravenel and Besson, "Youth training in European football".

2. Littlewood, Mullen and Richardson, Football labour migration.

3. Green, "Every boy's dream".

4. Poli, Ravenel and Besson, "Youth training in European football".

5. Premier League, "Elite player performance plan".

6. Bloom, "Developing talent in young people".

7. Premier League, "Elite player performance plan".

8. Relvas et al., Organizational structures and working practices; Richardson et al., "Sociological and Cultural Influences on Player Development".

9. Premier League, "Elite player performance plan".

10. Ibid., 59.

11. Relvas et al., Organizational structures and working practices; Richardson et al., "Sociological and Cultural Influences on Player Development".

12. Richardson et al., "Sociological and Cultural Influences on Player Development".

13. Wylleman and Lavallee, A developmental perspective on transitions faced by athletes.

14. Richardson et al., "Sociological and Cultural Influences on Player Development".

15. Relvas et al., Organizational structures and working practices.

16. Nesti and Littlewood, "Making your way in the game".

17. Richardson et al., "Sociological and Cultural Influences on Player Development".

18. Balyi, "Sport system building".

19. Ibid.

20. Relvas et al., Organizational structures and working practices; Richardson et al., "Sociological and Cultural Influences on Player Development".

21. Bloom, "Developing talent in young people"; Côté, The influence of family; Durand-Bush and Samela, "The development of talent in sport"; van Rossum, Talented in Dance.

22. Bloom, "Developing talent in young people".

23. van Rossum, Talented in Dance.

24. Bloom, "Developing talent in young people"; van Rossum, Talented in Dance.

25. Bloom, "Developing talent in young people".

26. van Rossum, Talented in Dance.

27. Ibid.

28. Nesti and Sulley, "Youth Development in Football".

29. Richardson et al., "Sociological and Cultural Influences on Player Development".

30. Nesti, "Existential Psychology and Sport: Theory and Application".

31. Nesti and Sulley, "Youth Development in Football".

32. Roderick, "The world of professional football".

33. Nesti and Littlewood, "Making your way in the game".

34. Cushion and Jones, Power, discourse, and symbolic violence.

35. Ibid.

36. Ibid., 148.

37. Parker, "Chasing the "big-time""; Cushion and Jones, Power, discourse, and symbolic violence.

38. Bloom, "Developing talent in young people"; van Rossum, Talented in Dance. 
39. Wylleman and Lavallee, "A developmental perspective on transitions faced by athletes".

40. Finn and McKenna, Coping with academy-to-first-team transitions; Mills et al., Identifying factors perceived to influence the development of elite youth football academy players; Morris, Tod and Oliver, From youth team to first team.

41. Premier League, "Elite player performance plan".

42. Hoepfl, Choosing qualitative research.

43. Jones, Hanton, and Connaughton, What is this thing called mental toughness.

44. Bloom, "Developing talent in young people"; van Rossum, Talented in Dance.

45. Roderick, "The world of professional football"; Relvas et al., Organizational structures and working practices; Potrac et al., 'Handshakes, BBQs, and bullets'; Richardson et al., An Examination of the Migratory Transition; Richardson et al., "Sociological and Cultural Influences on Player Development".

46. Patton, "Qualitative research \& evaluation methods".

47. Noy, Sampling Knowledge.

48. Braun and Clarke, Using thematic analysis.

49. Patton, "Qualitative research \& evaluation methods".

50. Braun and Clarke, Using thematic analysis.

51. Sparkes and Smith, "Qualitative research methods in sport".

52. Ibid.

53. Biddle et al., Research methods in sport.

54. Braun and Clarke, Using thematic analysis.

55. Ibid.

56. Sparkes and Smith, "Qualitative research methods in sport".

57. Relvas et al., Organizational structures and working practices; Richardson et al., "Sociological and Cultural Influences on Player Development".

58. Premier League, "Elite player performance plan".

59. Finn and McKenna, Coping with academy-to-first-team transitions; Nesti and Littlewood, "Making your way in the game"; Relvas et al., Organizational structures and working practices.

60. Richardson et al., "Sociological and Cultural Influences on Player Development".

61. Relvas et al., Organizational structures and working practices.

62. Premier League, "Elite player performance plan", 59.

63. Balyi, "Sport system building".

64. Ibid.

65. Ibid.

66. Richardson et al., "Sociological and Cultural Influences on Player Development".

67. Premier League, "Elite player performance plan".

68. Burgess and Naughton, Talent Development in Adolescent Team Sports.

69. Cumming et al., Is Winning Everything?

70. Ibid.

71. Ibid., 330.

72. Smith, Smoll and Curtis, "Coaching behaviors in little league".

73. Ibid.

74. Cumming et al., Is Winning Everything?; Smoll and Smith, "Coaching behavior research"

75. See Burgess and Naughton, Talent Development in Adolescent Team Sports. 
76. Helsen, van Winkel and Williams, The relative age effect.

77. Cumming et al., Is Winning Everything?

78. Stratton et al., "Youth Soccer", 201; Relvas et al., Organizational structures and working practices.

79. Ames, Achievement goals.

80. Duda and White, Goal Orientations and Beliefs.

81. Premier League, "Elite player performance plan".

82. Nesti, "Existential Psychology and Sport: Theory and Application".

83. Mills et al., Examining the development environments.

84. Henriksen, Stambulova and Roessler, Holistic approach to athletic talent.

85. Ibid.

86. Relvas et al., Organizational structures and working practices.

87. Henriksen, Stambulova and Roessler, Holistic approach to athletic talent, 220.

88. Henriksen, Stambulova and Roessler, Holistic approach to athletic talent.

89. Nesti et al., Critical moments.

90. Bar-Tal, "Siege mentality".

91. Wilson, Understanding organisational culture.

92. Richardson et al., "Sociological and Cultural Influences on Player Development".

93. Premier League, "Elite player performance plan", 42.

94. Bloom, "Developing talent in young people"; van Rossum, Talented in Dance.

95. Bloom, "Developing talent in young people". 


\section{References}

Ames, Carole. "Achievement Goals and the Classroom Motivational Climate." In Student Perceptions in the Classroom, edited by Dale H. Schunk and Judith L. Meece, 327-48. New Jersey, NY: Lawrence Erlbaum Associates Inc., Publishers, 1992.

Balyi, Istvan. "Sport System Building and Long-Term Athlete Development in British Columbia." Coaches Report 8, no. 1 (2001): 22-28.

Bar-Tal, Daniel. "Siege Mentality.” In The Encyclopedia of Peace Psychology, edited by Daniel J. Christie. Oxford: Blackwell Publishing, 2011. doi:10.1002/9780470672532.wbepp249.

Biddle, Stuart J.H., David Markland, David Gilbourne, Nikos L.D. Chatzisarantis, and Andrew C. Sparkes. "Research Methods in Sport and Exercise Psychology: Quantitative and Qualitative Issues.” Journal of Sports Sciences 19, no. 10 (January 2001): 777-809. doi:10.1080/026404101317015438.

Bloom, Benjamin S. Developing Talent in Young People. New York, NY: Ballantine, 1985.

Braun, Virginia, and Victoria Clarke. "Using Thematic Analysis in Psychology." Qualitative Research in Psychology 3, no. 2 (2006): 77-101. doi:10.1191/1478088706qp063oa.

Côté, Jean. "The Influence of the Family in the Development of Talent in Sport." The Sport Psychologist 13, no. 1995 (1999): 395-417. doi:10.1177/1527002502003003001.

Cumming, Sean P., Frank L. Smoll, Ronald E. Smith, and Joel R. Grossbard. "Is Winning Everything? The Relative Contributions of Motivational Climate and Won-Lost Percentage in Youth Sports.” Journal of Applied Sport Psychology 19, no. 3 (2007): 322-36. doi:10.1080/10413200701342640.

Cushion, Christopher, and Robyn L. Jones. "Power, Discourse, and Symbolic Violence in Professional Youth Soccer: The Case of Albion Football Club." Sociology of Sport Journal 23, no. 2 (2006): 142-61. doi:10.1123/ssj.23.2.142.

Darren J., Burgess, and Naughton Geraldine A. "Talent Development in Adolescent Team Sports: A Review.” International Journal of Sports Physiology and Performance 5, no. 1 (March 2010): 103-16. doi:10.1123/ijspp.5.1.103. 
Duda, Joan L., and Sally A. White. "Goal Orientations and Beliefs about the Causes of Sport Success among Elite Skiers.” The Sport Psychologist 6, no. 4 (December 1992): 334-43. doi:10.1123/tsp.6.4.334.

Durand-Bush, N., and J. Salmela. The Development of Talent in Sport. Edited by Robert N Singer, Heather Ann Hausenblas, and Christopher Janelle. 2nd ed. New York: John Wiley \& Sons, 2001.

Finn, Jon, and Jim McKenna. "Coping with Academy-to-First-Team Transitions in Elite English Male Team Sports: The Coaches’ Perspective.” International Journal of Sports Science \& Coaching 5, no. 2 (June 2010): 257-79. doi:10.1260/17479541.5.2.257.

Green, Chris. Every Boy's Dream: England's Football Future on the Line. London: A\&C Black, 2009.

Helsen, Werner F, Jan van Winckel, and A Mark Williams. "The Relative Age Effect in Youth Soccer across Europe.” Journal of Sports Sciences 23, no. 6 (2005): 62936. doi:10.1080/02640410400021310.

Henriksen, Kristoffer, Natalia Stambulova, and Kirsten Kaya Roessler. "Holistic Approach to Athletic Talent Development Environments: A Successful Sailing Milieu.” Psychology of Sport and Exercise 11, no. 3 (May 2010): 212-22. doi:10.1016/j.psychsport.2009.10.005.

Hoepfl, Marie C. “Choosing Qualitative Research: A Primer for Technology Education Researchers.” Journal of Technology Education 9, no. 1 (September 1, 1997): 47-63. doi:10.21061/jte.v9i1.a.4.

Jones, Graham. "What Is This Thing Called Mental Toughness? An Investigation of Elite Sport Performers.” Journal of Applied Sport Psychology 14, no. 3 (January 2002): 205-18. doi:10.1080/10413200290103509.

Littlewood, Martin, Chris Mullen, and David Richardson. "Football Labour Migration: An Examination of the Player Recruitment Strategies of the 'big Five' European Football Leagues 2004-5 to 2008-9." Soccer \& Society 12, no. 6 (2011): 788805. doi:10.1080/14660970.2011.609680.

Mills, Andrew, Joanne Butt, Ian Maynard, and Chris Harwood. "Identifying Factors Perceived to Influence the Development of Elite Youth Football Academy Players.” Journal of Sports Sciences 30, no. 15 (November 2012): 1593-1604. doi:10.1080/02640414.2012.710753. 
Mills, Andrew, Joanne Butt, Ian Maynard, and Chris Harwood. "Examining the Development Environments of Elite English Football Academies: The Players' Perspective.” International Journal of Sports Science \& Coaching 9, no. 6 (2014): 1457-72. doi:10.1260/1747-9541.9.6.1457.

Morris, Robert, David Tod, and Martin Eubank. "From Youth Team to First Team: An Investigation into the Transition Experiences of Young Professional Athletes in Soccer." International Journal of Sport and Exercise Psychology, March 4, 2016, 1-17. doi:10.1080/1612197X.2016.1152992.

Nesti, Mark. Existential Psychology and Sport: Theory and Application. Abingdon: Routledge, 2004.

Nesti, Mark, and Martin Littlewood. "Making Your Way in the Game: Boundary Situations in England's Professional Football World." In Critical Essays in Applied Sport Psychology, edited by David Gilbourne and Mark B. Andersen, 233-50. Champaign, IL: Human Kinetics, 2011.

Nesti, Mark, Martin Littlewood, Lisa O’Halloran, Martin Eubank, and David Richardson. "Critical Moments in Elite Premiership Football: Who Do You Think You Are?" Physical Culture and Sport. Studies and Research 56, no. 1 (January 1, 2012): 23-32. doi:10.2478/v10141-012-0027-y.

Nesti, Mark, and Chris Sulley. Youth Development in Football: Lessons from the World's Best Academies. Oxon: Routledge, 2014.

Noy, Chaim. "Sampling Knowledge: The Hermeneutics of Snowball Sampling in Qualitative Research.” International Journal of Social Research Methodology 11, no. 4 (October 2008): 327-44. doi:10.1080/13645570701401305.

Parker, Andrew. "Chasing the 'Big-Time': Football Apprenticeship in the 1990s." University of Warwick, 1996. http://wrap.warwick.ac.uk/36183/.

Patton, Michael Q. Qualitative Research \& Evaluation Methods. 3rd ed. London: Sage, 2002.

Poli, Raffaele, Loïc Ravenel, and Roger Besson. "Youth Training in European Football: A Comparative Analysis." CIES Football Observatory, no. 9 (2015). http://www.football-observatory.com/IMG/sites/mr/mr09/en/.

Potrac, P., R.L. Jones, D. Gilbourne, and L. Nelson. “'Handshakes, BBQs, and Bullets': Self-Interest, Shame and Regret in Football Coaching." Sports Coaching Review 1, no. 2 (October 2012): 79-92. doi:10.1080/21640629.2013.768418. 
Relvas, Hugo, Martin Littlewood, Mark Nesti, David Gilbourne, and David Richardson. "Organizational Structures and Working Practices in Elite European Professional Football Clubs: Understanding the Relationship between Youth and Professional Domains.” European Sport Management Quarterly 10, no. 2 (2010): 165-87. doi:10.1080/16184740903559891.

Richardson, Dave, Martin Littlewood, Mark Nesti, and Luke Benstead. “An Examination of the Migratory Transition of Elite Young European Football Players to the English Premier League.” Journal of Sports Sciences 30, no. 15 (2012): 1605-18.

Richardson, David, Hugo Relvas, and Martin Littlewood. "Sociological and Cultural Influences on Player Development.” In Science and Soccer: Developing Elite Performers, edited by A. Mark Williams, 3rd ed., 139-53. London: Routledge, 2013.

Roderick, Martin. The World of Professional Football: A Labour of Love? Oxon: Routledge, 2006.

Smoll, Frank L., and Ronald Edward Smith. "Coaching Behavior Research and Intervention in Youth Sports." In Children and Youth in Sport: A Biopsychosocial Perspective, edited by Frank L. Smoll and Ronald Edward Smith, 2nd ed., 211-34. Dubuque, Iowa: Kendall-Hunt, 2002.

Smoll, Frank L., Ronald Edward Smith, and Bull Curtis. "Coaching Behaviors in Little League Baseball.” In Psychological Perspectives in Youth Sports, edited by Frank L. Smoll and Ronald Edward Smith, 173-208. New Jersey, NY: John Wiley \& Sons, 1978.

Sparkes, Andrew C., and Brett Smith. Qualitative Research Methods in Sport, Exercise and Health: From Process to Product. Oxon: Routledge, 2014.

Stratton, Gareth, Thomas Reilly, A. Mark Williams, and Dave Richardson. Youth Soccer: From Science to Performance. London: Routledge, 2004.

Rossum, Jacques H. A. van. "Talented in Dance: The Bloom Stage Model Revisited in the Personal Histories of Dance Students." High Ability Studies 12, no. 2 (December 2001): 181-97. doi:10.1080/13598130120084320.

Wilson, Alan M. "Understanding Organisational Culture and the Implications for Corporate Marketing." Edited by John M.T. Balmer. European Journal of Marketing 35, no. 3/4 (April 2001): 353-67. doi:10.1108/03090560110382066. 
Wylleman, Paul, and David Lavallee. "A Developmental Perspective on Transitions Faced by Athletes." In Developmental Sport and Exercise Psychology: A

Lifespan Perspective, edited by Maureen R. Weiss, 507-27. Morgantown, WV:

Fitness Information Technology, 2004. doi:10.1037/spy0000022. 